\title{
Hands-on Horticulture: A Course for Building Enrollments in Plant Science Courses
}

\author{
Marvin P. Pritts ${ }^{1}$
}

\begin{abstract}
AdDITIONAL INDEX WORDS. campus grounds, culinary experience, experiential learning, gardening, recruitment, well-being

Summary. A course was developed at Cornell University for the purpose of attracting nonmajors from across the university, instilling in them an appreciation for horticulture and then encouraging them to take additional horticulture and plant science courses. The course incorporates many engaging and interesting horticultural activities, with scientific concepts and horticultural techniques conveyed almost exclusively through hands-on instruction using the campus as a laboratory. Experiential learning and culinary experiences are key components of the course. Student evaluations are very high (5-year average of 4.94/5.00 with five representing "excellent"), and the class fills to capacity each spring semester with diverse students from across campus. Enrollment in other horticulture classes has increased since the course has been offered. Forty-three percent of students who took Hands-On Horticulture as a freshman, sophomore, or junior subsequently enrolled in at least one other plant science course. Participating horticulture faculty also find the class to be fertile ground for recruiting research and field assistants. Students report an increase in well-being and reduction in stress while taking the course, and write about how their worldview has changed after the course experience. This class has allowed students to discover or rediscover their role and connection to nature while simultaneously providing them horticultural skills and understanding of scientific principles.
\end{abstract}

$\mathrm{M}$ any university agriculture programs, including horticulture, are experiencing a decline in enrollment (Hansen et al., 2007). Dole (2015) surveyed 54 undergraduate programs offering 4-year horticulture degrees and found that twice as many schools had declining enrollments than increasing enrollments, with $37 \%$ staying the same over the past 5 years. The public harbors misperceptions about agriculture (Pew Research Center, 2017; Terry and Lawver, 1995), and these negative perceptions may be contributing to lower enrollments in plant science classes. Meyer et al. (2016) report only $26 \%$ of phone survey respondents strongly agreed with the statement "horticulture is a diverse area of study, and it offers viable, fulfilling and respected career paths that I would recommend to others" and less than half of the college age demographic were familiar with the word "horticulture." A contributor to this misperception is

Horticulture Section, School of Integrative Plant Science, Cornell University, Ithaca, NY 14886

Thanks to Marcia Eames-Sheavly and Don Rakow for their helpful reviews and to Lisa Parsons who extracted the data on course selection of students.

${ }^{1}$ Corresponding author. E-mail: mpp3@cornell.edu. doi: 10.21273/HORTTECH03820-17 a lack of knowledge about what horticulture involves; hence, efforts like Seed Your Future: Promoting Horticulture in the United States (Seed Your Future, 2017) have been established. A widely accepted assumption is if young people only knew what horticulturists do, more would be interested in studying the subject and having a career in horticulture.

Whereas high school students are one potential source of new recruits for university horticulture programs, another is students already enrolled at one's institution. These students have already matriculated, but often are disappointed with the original discipline they started with freshman year. With some effort, these students may be convinced to change their course of study if they are offered classes and activities that engage and excite them. At Cornell University's College of Agriculture and Life Science (CALS), students apply to a major before admission. About $20 \%$ of students who apply to a major as prefreshmen change their major before graduating and a portion of these (4-6 students per year) transfer to plant sciences (CALS Registrar, personal communication). Dole's 2015 survey results indicate some programs have been able to increase their enrollments, although the reasons for these increases were not determined from the survey (Dole, 2015).

Bradley et al. (2003) offered a course at the University of Florida to attract nonmajors and enrollments increased to 100 students per semester. Other universities have developed similar courses to attract nonmajors; these are often organized around scientific principles, industry or careers, or they take place at a designated site on campus (McGann and Berghage, 2004; VanDerZanden and Cook, 1999). We developed a broad, experienced-based course to attract nonmajors, but were also interested to know if students who took this course would enroll in additional plant science courses, even if such courses were not required for their major. Investing in such courses may contribute to slowing a decline in enrollment or increasing student numbers in other horticulture classes.

\section{Course overview}

The objectives of this course are to 1 ) instill a life-long appreciation for how plants and gardening can enhance well-being through recreation, esthetic and culinary experiences and a familiarity with horticulture techniques; 2) generate excitement about plants and explain the many ways horticulture touches our lives; 3 ) demonstrate how horticultural principles are applied to improve plant growth, health, and appearance; and 4) become fluent in the use of biological terms and scientific principles used in gardening. Hands-On Horticulture is taught in a 4-h block, once per week on Friday afternoon. This time frame enables students to learn about a horticultural concept and then immediately implement the concept in an experiential context.

\section{Materials and methods}

Plant and agricultural science students are excluded from enrolling the course and seniors are not allowed to pre-enroll. The reasons for these exclusions are that plant science and agriculture students are already familiar with horticulture principles and second-semester seniors will be graduating so cannot take additional courses. Also, when students realize that there are no plant or agriculture students in the class, they may be 
more willing to ask questions about basic concepts without fear their question may appear to be naive. The course always fills to the enrollment cap (30 students). The class appears to be more ethnically diverse than the population of plant science majors as it attracts students from across the university. The university is comprised of $39.5 \%$ domestic Caucasians whereas $71 \%$ of plant science majors are members of this group. Data on the ethnicity of individual students in a class are not made available to the instructor.

Hands-On Horticulture exposes students to some of the most interesting and exciting aspects of horticulture with a goal of attracting them to additional horticulture and plant science courses. Hands-On Horticulture is an elective course and does not fulfill any distribution requirement in any college, and attracts students from throughout the university (Table 1). Teaching horticulture principles begins with experiences that take place at multiple locations on campus and then incorporates scientific concepts and industry perspectives to help students understand the experience (Table 2 ). This approach seems to appeal to students in other colleges who are intimidated by courses with a heavy focus on scientific principles.

To create an environment that facilitates experiential learning, students work in small groups from the very first day of class, including making introductions. Subsequent activities, such as pruning trees on campus or planting seeds, also require group efforts. Grafting hibiscus (Hibiscus rosa-sinensis) requires students share scions among each other. About 75\% of the hanging baskets students make are donated to underserved families in the area. An environment of sharing and helpfulness is created which, in turn, is reflected in students helping

Table 1. Cornell University colleges represented by undergraduate students enrolled in Hands-On Horticulture in 2015-17 (77 students).

\begin{tabular}{lc}
\hline Colleges represented & Proportion of students (\%) \\
\hline Agriculture and Life Sciences & 36 \\
Arts and Sciences & 23 \\
Architecture, Art, and Planning & 3 \\
Engineering & 4 \\
Hotel and Restaurant Management & 26 \\
Human Ecology & 8 \\
\hline
\end{tabular}

each other with activities, as the instructor and teaching assistant move around the room serving in a coaching role. Students are free to use the restroom or get a drink at any time, as hot beverages are always available in the back of the room.

During the semester, seven guest instructors are invited to participate in at least part of a class. Guest instructors are encouraged to ask questions during their presentation, particularly reflective questions. For example, on the first day of class, students are asked to think about what gardens mean to them. Is gardening a solitary activity or one that facilitates engagement with friends and family? Is gardening work or play? How might a garden reflect your personality? Do you enjoy watching a garden evolve over time or do you want instant gratification? Having students respond to questions that have no right or wrong answer encourages dialog and establishes an atmosphere that facilitates creativity and inquisitiveness (Pritts and Eames-Sheavly, 2016).

\section{Course detail}

The same template is followed for each class. The first activity is a simple three question quiz on last week's topic. The objective of the quiz at the beginning of class is it motivates students to arrive on time, it provides a record of attendance, and it allows for the answers to be reviewed immediately, reinforcing last week's learning. The second activity is an introduction to the concept or practice that will be explored. A typical introduction ranges from 15 to $25 \mathrm{~min}$. These minilectures are supplemented with class discussion and occasional on-line videos (Table 3 ). This is followed by engagement in the activity itself with a demonstration and then coaching by the instructor and teaching assistant. Horticulture

Hortlechnology • October 2017 27(5) principles are reinforced verbally during the activity. Each class also has a culinary experience in which students are presented with a food related to the subject being taught. A goal is to serve a food the students may not have consumed before (Table 2) and have them practice connecting what they eat with how it is produced. Most foods are prepared by the instructor and teaching assistant the night before class. Some ingredients (e.g., single source chocolates and edible insects) are not available locally so are mail ordered.

The first class is an introduction to the history of gardening and the meaning of gardens. Students are divided into 10 groups of three and each group is given colored markers, a large poster board, and a detailed verbal description of a garden from a particular place and time in history including the plants that were grown; for example, Egyptian gardens 5000 BCE, Babylonian 1000 BCE, Greek 300 BCE, Roman 100 AD, Islamic $600 \mathrm{AD}$, Chinese $600 \mathrm{AD}$, Japanese $1100 \mathrm{AD}$, Renaissance $1500 \mathrm{AD}$, English $1600 \mathrm{AD}$, and America today. Students are given time to read the description, an hour to draw their particular garden as a group, and then go to the front of the class in chronological order and describe the garden and its meaning during that period in history. Within a short amount of time, the class begins to understand the sophistication of earlier civilizations, how various plants moved around the world along trade routes, the various philosophies of nature between East and West, the important role of religious symbolism reflected in gardens, how gardens in the past were used for much more than producing food, and how today's lawns and gardens in the West are different from those in the past and from much of the rest of the world. Also, included in the first class is a presentation on the contemporary meaning of gardens and an introduction to soils, as this is important background for most of the remaining topics. Each student is given a pot of soil and asked to examine it closely, using their sense of touch, smell, and sight, and then describe what they observe. With probing questions, students deduce that soil consists of minerals, air, water, and organic matter. 


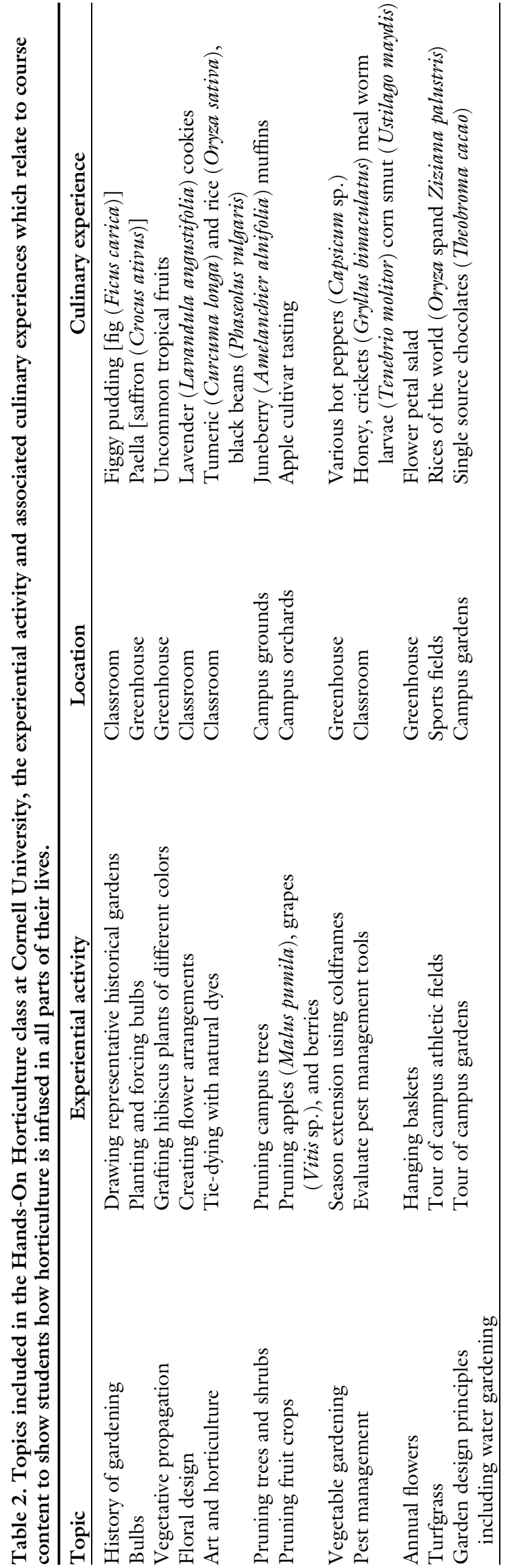

The class on season extension and vegetables requires some advanced planning. About one month before the scheduled class, students plant seeds of six different vegetable and flower species representing a range of cold hardiness. Seedlings are then transplanted into larger pots before the actual class on season extension. Then plants are set outside in early spring and protected with various plastics, row covers and coldframes. After another month, plant performance is evaluated. Students learn first-hand that tomato (Solanum lycopersicum) is not cold hardy, but kale (Brassica oleracea) is and that some protective strategies work better than others.

Given that this course is offered during the spring semester in upstate New York, there are few pests to observe at this time of year. As an alternative to observing pests, students are given a pest control product purchased from a local garden center. Each student has a different product. They are given time to explore the following questions: What is the product? What is the target organism? How does it work? Is it considered acceptable for organic growers? What precautions must one take when using the product? In addition to learning how to read a label, students are presented with a myriad of ways pests are managed. Most revealing is their discovery that many products that contain pesticides are acceptable to organic growers. Many students assume organic products are not treated with pesticides. Watching short videos about the various topics helps students relate to the subject and generates interest in the science.

The class on turfgrass is the most surprising to students. Grass is something most students take for granted, but when they visit the various sports fields on campus and learn about the interaction between athletic shoes and turf, the advantages and disadvantages of artificial turf, and the expense involved in preparing fields for soccer, football, baseball, and lacrosse, their interest is piqued. They also see first-hand the places where grass is having difficulty growing on campus and they learn why. Students often mention this particular class as one of the highlights of the course. 
Table 3. Useful online videos for the Hands-On Horticulture class at Cornell University that demonstrate interesting horticultural principles and promote discussion.

\begin{tabular}{lll}
\hline Topic & \multicolumn{1}{c}{ URL } & Reference \\
\hline Painting with soil & https://www.youtube.com/watch?v=MVgFFli814A & Cornell University (2015) \\
Flower volcano & https://www.youtube.com/watch?v=q2DdtkDK7w0 & Sony (2013) \\
Keukenhof Gardens & https://www.youtube.com/watch?v=3EVLdCx_ums & Grecko (2016) \\
Cut flower industry & https://www.youtube.com/watch?v=X43U6trzjDE & Velez (2012) \\
Titan arum flowering & https://www.youtube.com/watch?v=8XkgYGencEI & Cornell University (2016) \\
Living root bridges & https://www.youtube.com/watch?v=UmHiQs_G4hs & Mangalore (2015) \\
Grafting fruit trees & http://video.nationalgeographic.com/video/news/ & National Geographic (2015) \\
& $150720-40$-fruit-tree-vin & Full Grown (2015) \\
Growing chairs & https://www.youtube.com/watch?v=lvq4FKyQhSk & Schwartzberg (2011) \\
Beauty of pollination & https://www.youtube-nocookie.com/embed/xHkqledcbk4 & National Geographic (2007) \\
Insects as food & https://www.youtube.com/watch?v=12-wzFlqzno & 5StarDesignShow (2008) \\
Home landscaping & https://www.youtube.com/watch?v=FUbJBpoK4HY & Requitina (2014) \\
Pesticides on food & https://www.youtube.com/watch?v=2gI0QqqkfHs &
\end{tabular}

Hands-On Horticulture takes advantage of the campus grounds for many of the activities. In addition to sport fields, students learn to prune using various campus plantings and orchards. Students visit the plant conservatory and greenhouse hydroponic and aquaponic operations. Students learn about design principles and different types of landscape plants by visiting the various gardens on campus. Students passing by the campus activity often stop to ask what is occurring and this provides an opportunity to promote the class. The class activities have been featured several times in university social media. The use of the campus grounds as a living and working laboratory is not new (Bassuk and Trowbridge, 2010), but does require close collaboration with the university grounds and athletic departments.

After many of the classes the students are able to take a horticultural item home with them: a floral arrangement, a grafted hibiscus plant, vegetable transplants, a hanging basket, a dyed scarf or shirt, and pots of daffodils (Narcissus sp.), tulips (Tulipa sp.), and amaryllis (Amaryllis belladonna). These items serve as advertisements for the course as housemates and dormitory residents are curious about the abundance of plants coming back to the residence at the end of each week.

The last class of the semester is scheduled on Saturday instead of Friday. It is an all-day field trip consisting of visits to horticulture professors' home gardens. Here students see much of what they learned in class put into practice. It is also an enjoyable way to end the semester, and it generates further interest in taking other horticulture classes from the professors we visit. Few other faculty at the university host large groups of students at their homes, so this helps create a reputation of horticulture as a welcoming unit.

This course involves a significant amount of time to prepare class materials, make arrangements for visits and activities, and to prepare food. The course is also one of the most expensive in our unit; a budget of about $\$ 3000$ is used for 30 students and includes materials (cut flowers, bulbs, seeds, culinary ingredients, and plant dyes), greenhouse rental, and buses for field trips. Establishing this course also required an initial purchase of grafting tools, loppers and hand pruners. A laboratory fee is not requested although this remains an option. Maintaining and updating the course web site with presentations, web links, lecture supplements, and recipes also require a time commitment.

\section{Student assessments}

The course uses several types of assessments. The first are the quizzes described earlier that mostly count for attendance. Students do not lose points if they get a question wrong if they attempted to provide a thoughtful answer. Quizzes are intended to be used as a learning tool to review the previous week's concept. A second assessment is a series of reflection papers that students write throughout the semester. Students are told the purpose of this assignment is to reflect on how something learned in class has had an impact. This reflection could be on a new perspective gained or a new skill or interest acquired through taking the course, or even on something not appreciated. Suggested prompts for the essay are, "I believe this hands-on experience has had an impact on my learning because ..." or "I never realized that ..." or "This topic was confusing to me because ..." These reflection papers give the instructor insight into how students learn and what subjects are most impactful.

A third assessment is a spring break photo project. Students take a photograph of something of horticultural significance during their travels and write a paragraph about the subject. These photographs are consolidated, shown in class, and each student is given $1 \mathrm{~min}$ to describe where they took the photograph and why is has horticultural significance. Past examples have included: cherry (Prunushybrids) blossoms (Washington, DC); poor pruning jobs on trees and shrubs at Bellagio (Las Vegas, $\mathrm{NV}$ ); topiary, floral displays, fruit orchards, and vineyards at The Land in Disney World (Orlando, FL); sports fields and various formal gardens. The learning outcome from this exercise is to demonstrate that horticulture is all around us if we open our eyes to it.

The fourth assessment tool is a final project. Students are given the option of developing a web site, writing an article, reviewing a book, or doing a project related to horticulture. The objective is to encourage students to expand on what they learned in class and perhaps even 
implement their new knowledge in a garden context. Examples of past demonstration projects have included: painting with living moss, seed mandalas, creating multicolored roses (Rosa sp.), and building a water garden, sod sculpture, or terrarium. Some students have included a culinary component such as tea (Camellia sinensis) tasting. Students occasionally design an ornamental garden for their sorority or fraternity. Some prefer to write essays on a particular crop not grown in New York, like coconut (Cocos nucifera) or ginger (Zingiber officinale), or a particular feature such as living walls or green roofs, or an aspect of plants such as Chinese medicinal herbs. One student wrote new verses to a popular song based on the class on water gardening. Then a cappella group performed the song and posted it to a file sharing web site (YouTube. com, San Bruno, CA) for others to enjoy. The goal of this assignment is for the students to independently explore some aspect of horticulture and convince the instructor that they gained new knowledge and insight from the project. Students control with the instructor before embarking on the project to ensure that it is appropriate and not too broad.

\section{Course impact and assessment}

The university asks students to evaluate each course at the end of the semester. In addition, in 2017, students were asked to respond to nine questions about how the course has impacted their perspective about plants and their intent to take other plant science classes (Table 4). Finally, a data request was made to Cornell Information Technologies to identify how many students that took Hands-On Horticulture subsequently took an additional plant science class. Transcripts of all nonseniors who took Hands-On Horticulture in 2014, 2015, and $2016(n=$ 80 ) were examined to determine what percentage took a subsequent course listed under the plant science prefix. This included both structured and unstructured (internships and research) credits.

\section{Results and discussion}

On end-of-the-year course evaluations offered to all students by the university, on a scale of 1 to 5 with 1 representing very poor and 5 representing excellent, the class average in response to the statement "Course deserves an overall rating of" has been $4.94,5.00,4.82,4.94$, and 5.00 for each of the past 5 years, respectively. In a separate survey administered in 2017, students were asked about their intention to take additional horticulture courses (Table 3 ). On a scale of 1 to 5 with 1 representing "definitely no" and 5 representing "definitely yes," students strongly indicated an intention to take more plant-related courses $(4.4 / 5)$, and that the course made them more aware of the world around them (4.7), that it changed their perspective about the campus (4.6), that they were more willing to try unfamiliar foods (4.4), and that it increased their life skills and confidence in gardening (4.6). All but one student indicated the course relieved stress (selected from the following choices: stress relief, no stress, a little stress, some stress, and great stress) and all surveyed students indicated they would definitely recommend the course to another student (Table 4). Data indicate $43 \%$ of nonseniors (34/ 80) who enrolled in Hands-On Horticulture over the past 3 years eventually enrolled in another plant science course. In addition, faculty have found this class to be a fertile recruiting ground for summer interns and field assistants.

The class has encouraged students to slow down and observe the world, particularly the campus they walk through each day (Table 4). Several students have written to the university grounds department to thank them for all the work they now realize goes into managing the campus landscape. A surprising result of teaching this class has been the number of comments in reflection papers about impacts beyond increased confidence in managing home grounds and gardens These impacts are difficult to quantify, but can be captured in comments from student reflection papers from 2016.

\section{Excerpts from reflection papers}

"One way that I've started to implement this class into my life is by slowing down my walking pace around campus. Rather than put my head down and speed-walk to class, I've been making a conscious effort to look around and appreciate the beautiful natural areas surrounding campus. I think this may prove as an effective stress management technique for me as I already feel as if my quality of life has improved since last semester."

"How many times a day do students at Cornell take the time to stop and appreciate all the natural beauty that surrounds campus? I bet not much. Anywhere nowadays it's nearly impossible for people to take time out of their day to appreciate the Earth. This class has taught me to have an open eye everywhere I walk. I decorate my room with plants, talk about plants, and appreciate plants because

Table 4. Survey responses of students enrolled in Cornell's Hands-On Horticulture class for Spring 2017 regarding how learning outcomes were met and their intention to take additional plant science courses. On a scale of 1 to 5 with "1" representing "definitely no" and 5 "definitely yes" students were asked to respond to the following statements (25 students).

Statement

Survey response (1 to 5 scale)

As a result of taking this course

I am likely to take another horticulture course

4.4

I am more aware of the world around me

I will recommend this course to another student

My perspective and appreciation of the campus has changed

I am more willing to try foods that I never would have considered eating before

My life skills and confidence in gardening has increased

If I could start my Cornell career over again, I would take more plant courses 
of this class. However, before this class I never had a reason to stop and appreciate a beautiful landscape or floral design. This class has taught me to think outside the box and stop to appreciate Earth's natural beauty."

"I had never really seen the true creative art and expression that comes with building a garden. I had always considered gardening to be something that older people, especially women did during their free time at home. Now, as I sit in my apartment surrounded by budding plants that I grew, I realize that I too find enjoyment and appreciation in fostering life and color through nature. I had been somewhat indifferent about the thousands flowers around me. I merely walked through and observed casually, without much appreciation to the design, care, and nature in the spaces around me. But this class has completely shifted my view on what gardening is like. With gardening, your canvas is a living, growing, community that is ever changing."

"Happiness is a mental or emotional state of well-being defined by positive or pleasant emotions ranging from contentment to intense joy. I define happiness by something that makes me smile uncontrollably. Up until recently, I never had an appreciation for flowers and plants. HandsOn Horticulture has opened my eyes to the complexity and beauty of plants. More importantly, however, this class has also introduced me to a new found happiness. The feeling of not being able to control your smile is an amazing feeling. I am so happy that I took this class, because happiness is key, and finding new sources of it is what life's about."

"I would have never thought that one day, a friend and I would have a rather lengthy conversation about, well, grass. I can no longer walk on grass and see it, and to a larger extent nature, as a completely separate entity from me. I have come to realize what one does greatly affects the other and that our histories are so closely intertwined."

\section{Conclusions}

A course similar to Hands-On Horticulture could be developed and offered at any university using the campus grounds as a teaching laboratory.
The instructor does not need to be an expert on every subject to teach this course, and when less confident, a guest lecturer can be brought in to assist. Guest lecturers also provide a way for students to get to know other faculty who can then recruit for their class. Although somewhat expensive, the course is considered a good investment and has continued for 12 years. Courses such as this can attract students from across the university (Bradley et al., 2003). Almost half of non-plant science students who take this class will seek out another related class. The expense and time commitment have resulted in a unique course that teaches life skills and often alters the perspective of young people who previously have had minimal exposure to plants.

\section{Literature cited}

5StarDesignShow. 2008. Urban garden. 2 Aug. 2017. <https://www.youtube. com/watch?v=FUbJBpoK4HY>.

Bassuk, N. and P. Trowbridge. 2010. Creating the urban Eden: Sustainable landscape establishment in theory and practice. Hort Technology 20:485-486.

Bradley, J.C., D. McConnell, M. Kane, and G. Miller. 2003. Development and implementation of a nonmajors horticultural survey class. HortTechnology 13:196-199.

Cornell University. 2015. For the love of soil. 2 Aug. 2017. <https://www. youtube.com/watch?v=MVgFFli814A>.

Cornell University. 2016. 'Wee Stinky' first night. 2 Aug. 2017. <https://www. youtube.com/watch?v=8XkgYGencEI $>$.

Dole, J.M. 2015. Status of student numbers and program identity at two-year and four-year horticultural programs. Amer. Soc. Hort. Sci. Nwsl. 31(1):5-6.

Full Grown. 2015. Full Grown promo. 2 Aug. 2017. <https://www.youtube. $\mathrm{com} /$ watch?v=lvq4FKyQhSk>.

Grecko, V. 2016. Keukenhof 2016 (the garden of Europe). 2 Aug. 2017. <https://www.youtube.com/watch? $\mathrm{v}=3 \mathrm{EVLdCx}$ _ums $>$.

Hansen, N., S. Ward, R. Khosla, J. Fenwick, and B. Moore. 2007. What does undergraduate enrollment in soil and crop sciences mean for the future of agronomy? Agron. J. 99:1169-1174.
Mangalore, A.M. 2015. Living root bridges - Cherrapunji, Meghalaya, India. 2 Aug. 2017. <https://www.youtube. com/watch?v=UmHiQs_G4hs>.

McGann, M.R. and R.D. Berghage. 2004. The Pennsylvania State University medieval garden: Using a specialized garden as an alternative teaching and learning environment. HortTechnology 14:155-160.

Meyer, M.H., D. Needham, J. Dole, B. Trader, J. Fox, M. Conley, M. Neff, and J. Shaw. 2016. Importance of horticulture and perception as a career. Hort Technology 26:114-120.

National Geographic. 2007. Insect candy. 2 Aug. 2017. <https://www.youtube. com/watch?v=12-wzFlqzno $>$.

National Geographic. 2015. This crazy tree grows 40 kinds of fruits. 2 Aug. 2017. <http://video.nationalgeographic.com/ video/news/150720-40-fruit-tree-vin>.

Pew Research Center. 2017. Major gaps between the public, scientists on key issues. 2 Aug. 2017. <http://www. pewinternet.org/interactives/publicscientists-opinion-gap/>.

Pritts, M.P. and M. Eames-Sheavly. 2016. Fostering creativity in the horticulture classroom. HortTechnology 26:358-364.

Requitina, M. 2014. John Stossel much ado about nothing with Bruce Ames. 2 Aug. 2017. <https://www.youtube. $\mathrm{com} /$ watch?v=2gI0QqqkfHs $>$.

Schwartzberg, L. 2011. The beauty of pollination. 2 Aug. 2017. <https://www. youtube-nocookie.com / e mbed / xHkqledcbk4>.

Seed Your Future. 2017. Promoting horticulture in the U.S. 2 Aug. 2017. $<$ http://www.seedyourfuture.org $>$.

Sony. 2013. Sony $4 \mathrm{~K}-$ Four times the detail. 2 Aug. 2017. <https://www.youtube. com/watch?v=q2DdtkDK7w0 $>$.

Terry, R. and D.E. Lawver. 1995. University students' perceptions of issues related to agriculture. J. Agr. Educ. 36:6471.

VanDerZanden, A.M. and T. Cook. 1999. A multifunctional horticulture teaching garden at Oregon State University. Hort Technology 9:549-551.

Velez, L.C. 2012. Colombia's flower industry blooming. 2 Aug. 2017. <https://www. youtube.com/watch?v=X43U6trzjDE $>$. 